\title{
Globe stability during simulated vitrectomy with valved and non-valved trocar cannulas
}

\author{
This article was published in the following Dove Press journal: \\ Clinical Ophthalmology \\ 21 September 2015 \\ Number of times this article has been viewed
}

\author{
Dina Joy Abulon' \\ Martin Charles ${ }^{2}$ \\ Daniel E Charles ${ }^{2}$ \\ 'Global Medical Affairs, Alcon \\ Laboratories, Inc., Lake Forest, \\ CA, USA $;{ }^{2}$ Centro Oftalmológico \\ Dr Charles, Buenos Aires, Argentina
}

Correspondence: Martin Charles Centro Oftalmológico Dr Charles, Riobamba 84I, CIII6ABA Buenos Aires, Argentina

Tel +54 || 4I296000

Email doccharles@gmail.com
Purpose: To compare the effects of valved and non-valved cannulas on intraocular pressure (IOP), fluid leakage, and vitreous incarceration during simulated vitrectomy.

Methods: Three-port pars plana incisions were generated in six rubber eyes using 23-, 25-, and 27-gauge valved and non-valved trocar cannulas. The models were filled with air and IOP was measured. Similar procedures were followed for 36 acrylic eyes filled with saline solution. Vitreous incarceration was analyzed in eleven rabbit and twelve porcine cadaver eyes.

Results: In the air-filled model, IOP loss was $89 \%-94 \%$ when two non-valved cannulas were unoccupied versus $1 \%-5 \%$ when two valved cannulas were unoccupied. In the fluid-filled model, with non-valved cannulas, IOP dropped while fluid leaked from the open ports. With two open ports, the IOP dropped to $20 \%-30 \%$ of set infusion pressure, regardless of infusion pressure and IOP compensation. The IOP was maintained in valved cannulas when one or two ports were left open, regardless of IOP compensation settings. There was no or minimal fluid leakage through open ports at any infusion pressure. Direct microscopic analysis of rabbit eyes showed that vitreous incarceration was significantly greater with 23-gauge non-valved than valved cannulas $(P<0.005)$, and endoscopy of porcine eyes showed that vitreous incarceration was significantly greater with 23 -gauge $(P<0.05)$ and 27 -gauge $(P<0.05)$ non-valved cannulas. External observation of rabbit eyes showed vitreous prolapse through non-valved, but not valved, cannulas.

Conclusion: Valved cannulas surpassed non-valved cannulas in maintaining IOP, preventing fluid leakage, and reducing vitreous incarceration during simulated vitrectomy.

Keywords: IOP, fluid leakage, vitreous incarceration

\section{Introduction}

A closed surgical system is the standard of care in many small-incision ophthalmologic procedures, such as vitrectomy. Previously, when using 20-gauge incisions, the sclera acted as a better valve than open cannula systems. Although entering more distally through the cannula has the advantage of avoiding direct contact with the vitreous base, an open system is a significant cause of concern for retinal surgeons because of the increased risk of complications due to fluid egress, such as hypotony, wound leakage, vitreous incarceration, and turbulence.

Fluid-air exchange is a surgical maneuver commonly used for endodrainage of subretinal fluid in retinal detachment surgery; prior to air-gas exchange in macular hole surgery; to improve visualization of the periphery in diabetic panretinal photocoagulation; during photocoagulation of a peripheral break; as a tamponade; and to prevent fluid leakage from the wound following minimally invasive vitrectomy. While working under air during vitrectomy, temporary globe collapse is often seen under open cannula conditions, such as instrument exchange with non-valved cannulas. 
This collapse is more frequently observed in young patients due to a compliant sclera, myopic eyes, or small orbits, in which intraorbital pressure may be higher due to the effects of anesthesia (Figure 1A). When the instruments are inserted into the eye and the non-valved cannulas are occupied, the eye suddenly reinflates (Figure 1B). ${ }^{1-3}$

Another frequent complication of retinal surgery is vitreous incarceration. ${ }^{4}$ For example, anterior vitreous incarceration into cannulas has been observed during 25-gauge vitrectomy in eyes with asteroid hyalosis. ${ }^{5}$ Even in minimally invasive pars plana vitrectomy, incarcerated vitreous can cause significant anterior-posterior vitreous traction, ${ }^{6}$ and vitreous incarceration with non-valved sutureless incisions has been associated with peripheral retinal tears, acute endophthalmitis, and fibrovascular proliferation..$^{7-9}$

Various surgical techniques have been reported to minimize vitreous incarceration. Vitreous shaving around sclerotomy sites has been found to reduce vitreous incarceration following pars plana vitrectomy. ${ }^{10}$ A study in patients evaluating the sclerotomy site endoscopically through another cannula in 32 eyes that underwent 23-gauge nonvalved cannula vitrectomy found no vitreous incarceration in 30 eyes (94\%) when one cannula was removed with insertion of a light probe, with only minimal vitreous incarceration observed in the other two eyes. ${ }^{11}$ Experimental models in porcine cadaver eyes showed that interposing a light probe through the cannula during its removal reduced the rate and severity of vitreous incarceration. ${ }^{12,13}$

Recently developed valved trocar cannulas preserve the closed surgical system regardless of instrument exchange, thereby offering a promising alternative to non-valved instruments. The purpose of this study was to compare the effects of valved and non-valved cannulas on intraocular pressure (IOP) in air-filled rubber eyes; IOP and flow rate in fluid-filled acrylic eyes; and vitreous incarceration in animal cadaveric eyes.

\section{Methods \\ Air-filled model}

Hollow rubber eyes (model JDE1293; Vitreoretinal Training System, Redland, UK) were used to simulate IOP fluctuations during vitrectomy instrument exchange in an air-filled eye. In each of six eye models, four Edgeplus ${ }^{\circledR}$ trocar cannulas (Alcon Laboratories, Inc., Fort Worth, TX, USA) of the same size (23-, 25-, or 27-gauge) and type (valved or non-valved) were inserted at the 2, 4, 5, and 10 o'clock positions, $4 \mathrm{~mm}$ away from the limbus. No non-valved 27-gauge Edgeplus ${ }^{\circledR}$ cannulas were available, so the septum of a valved 27-gauge cannula was removed to replicate the non-valved condition.

The infusion cannula was attached to the cannula in the 4 o'clock position, and a differential pressure sensor (model PCE-P05; PCE Holding GmbH, Meschede, Germany) was inserted into the 5 o'clock cannula to capture IOP measurements.

For each test, the eye model was completely filled with air through the infusion cannula. The air infusion pressure on the CONSTELLATION ${ }^{\circledR}$ Vision System (Alcon Laboratories, Inc.) was set to $30 \mathrm{mmHg}$. Either one or two ports of the model eye were obstructed with a vitrectomy probe and/or endoilluminator to simulate open obstructed or unoccupied cannula conditions during vitrectomy instrument exchange. IOP was recorded for each test condition (no, one, or two obstructed ports), with each cannula type (valved
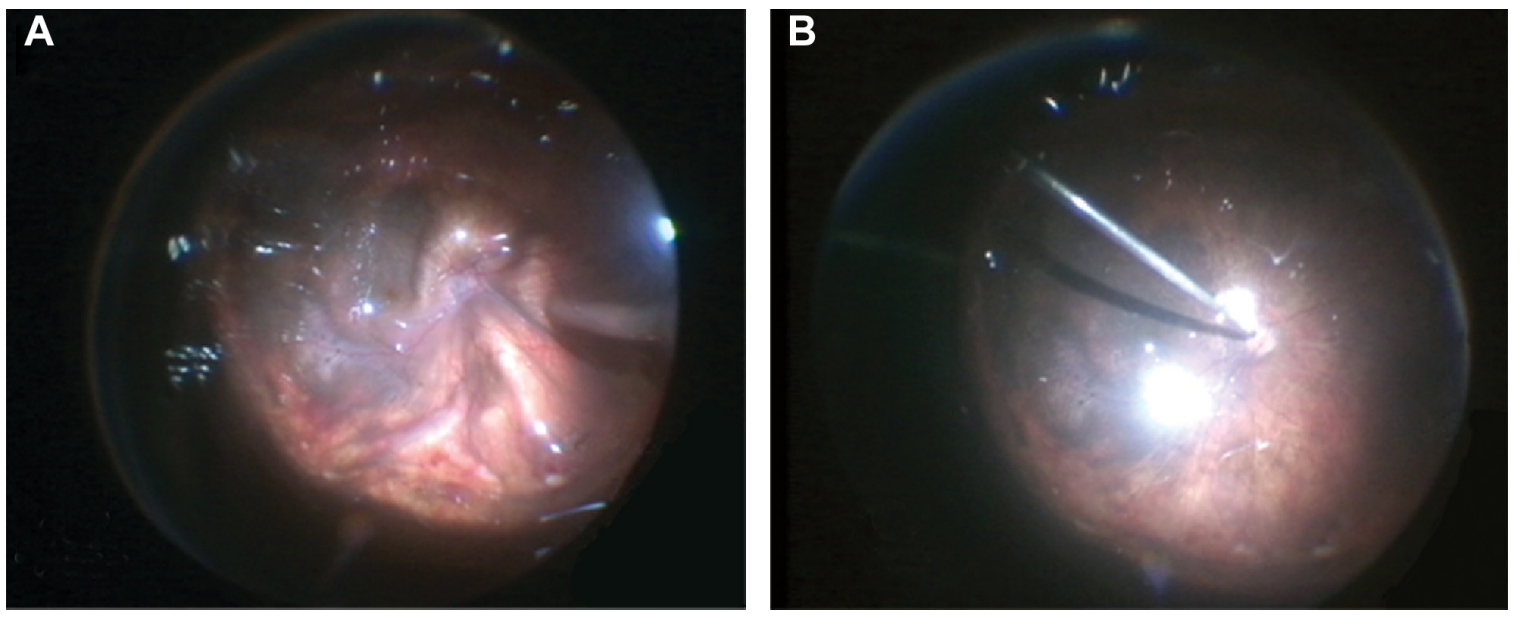

Figure I Photographs showing (A) temporary globe collapse under open-cannula conditions and (B) reinflation of the eye after non-valved cannulas are occupied while working under air. 
or non-valved), for each gauge. Average IOP and standard deviations were calculated, and valved and non-valved data were compared using Student's $t$-tests.

\section{Fluid-filled model}

Acrylic model eyes with three Edgeplus ${ }^{\circledR}$ trocar cannulas of the same size (23-, 25-, or 27-gauge) and type (valved or nonvalved) were used to simulate pars plana vitrectomy. Again, the septum of a valved 27-gauge cannula was removed to replicate the non-valved condition. Six eye models of each cannula size were compared ( $\mathrm{N}=36$ total). Eye models were assembled by fusing two $1 \times 1 / 4$-inch clear acrylic domes (Kit Kraft Inc., Studio City, CA, USA) into one hollow globe using Loctite 4014 adhesive (Henkel Corporation, Rocky Hill, CT, USA). At the top of the globe, three holes of the same size were drilled to replicate pars plana sclerotomies: one hole was created at the inferotemporal quadrant (8 o'clock position) and two superior holes were created at the 10 and 2 o'clock positions. The 25 -gauge cannulas required $0.58 \mathrm{~mm}$ holes; the 23 -gauge probes required $0.74 \mathrm{~mm}$ holes; and the 27-gauge probes required $0.42 \mathrm{~mm}$ holes. The appropriately sized valved or non-valved cannula was inserted into each drilled hole and secured using Loctite 4014 adhesive.

A fourth hole, $6.35 \mathrm{~mm}$ in diameter, was drilled at the bottom of the eye model, and a Honeywell 40PC015G pressure transducer was secured inside the hole to capture IOP measurements. The pressure transducer was connected to a power source and a LabView ${ }^{\mathrm{TM}}$ data acquisition board. Prior to data collection, the pressure transducer was calibrated using a Druck pressure calibrator. A fluid flow meter (model ME4PXN; Transonic Systems Inc., Ithaca, NY, USA) in line with the infusion tubing was connected to the LabView ${ }^{\mathrm{TM}}$ data acquisition board and relayed data to LabView ${ }^{\mathrm{TM}}$ software.

To visualize fluid dynamics during simulated vitrectomy instrument exchange, microbead motion was tracked in the acrylic globes with 23-, 25-, or 27-gauge trocar cannulas replicating three-port vitrectomy sclerotomies. Approximately $20 \mathrm{mg}$ of glass-coated $50 \mathrm{~g}$ microbeads (SoloHill Engineering, Inc., Port Washington, NY, USA) were injected into the $500 \mathrm{~mL}$ buffered saline solution (BSS) bottle. The infusion pressure was set to $30 \mathrm{mmHg}$. The infusion cannula was connected from the cassette to the plastic eye model. The globe was filled with BSS and air bubbles were eliminated and vented through the cannula. The eye model was mounted on an optical breadboard in front of a high-speed digital microscope (model VW-9000; Keyence
Corporation, Osaka, Japan). Digital imaging was adjusted until the portion of the cannula inside the eye (flow inlet) was focused within the field of view. Two sets of lights (LED Fiber Lites model LMI-6000; Dolan-Jenner Industries, Boxborough, MA, USA) were positioned around the acrylic globe to help visualize the microbeads. The Keyence recording parameters were set to $4,000 \mathrm{fps}$ and $1 / 8,000$ second shutter speed.

For each test, each eye model was completely filled with BSS. The infusion pressure on the CONSTELLATION ${ }^{\circledR}$ Vision System was activated. One or two ports of the model eyes were obstructed with a vitrectomy probe and/or endoilluminator to simulate obstructed or unoccupied cannula conditions during vitrectomy instrument exchange. The computer captured and saved flow rates and IOP for each test condition (no, one, or two obstructed ports) at each infusion pressure $(30,60,90$, or $120 \mathrm{mmHg})$, with each cannula type (valved or non-valved), for each gauge. Average flow, average IOP, and standard deviations were calculated, and valved and nonvalved data were compared using Student's $t$-tests.

Figure 2 shows the experimental setup.

\section{Vitreous-filled models}

\section{Direct microscopic visualization of vitreous incarceration in rabbit cadaver eyes}

Eleven rabbit cadaver eyes were obtained within 48 hours of enucleation and refrigerated prior to use. Each eye was secured to a Styrofoam head. The corneal epithelial cells were scraped using a $1.9 \mathrm{~mm}$ keratome to improve visualization of the posterior segment. Four 23-gauge sclerotomies at a $30^{\circ}$ angle to the limbus were created using Edgeplus ${ }^{\circledR}$ valved or non-valved trocar cannulas. For each test in each eye, the same size cannulas were used. Two valved cannulas were inserted at the 4 and 6 o'clock positions for the endoilluminator and infusion cannula, respectively. For side-by-side comparisons of vitreous incarceration, one valved cannula was inserted at the 8 o'clock position and one non-valved cannula at the 10 o'clock position. The infusion pressure was set to $30 \mathrm{mmHg}$, and $0.04 \mathrm{~cm}^{3}$ of pure triamcinolone was injected into the 8 o'clock valved cannula and 10 o'clock non-valved cannula, alternating their order during each test.

Methylcellulose was applied to the corneal surface. Zoom, focus, and magnification of the Merlin ${ }^{\circledR}$ Surgical System with a wide-angle $\mathrm{ACS}^{\circledR}$ lens (Volk Optical Inc., Mentor, $\mathrm{OH}$, USA) were adjusted for best visualization. The internal tip of each cannula was observed through the microscope for vitreous incarceration. Cannulas were moved to verify true internal incarceration into the inner lumen. Externally, one 


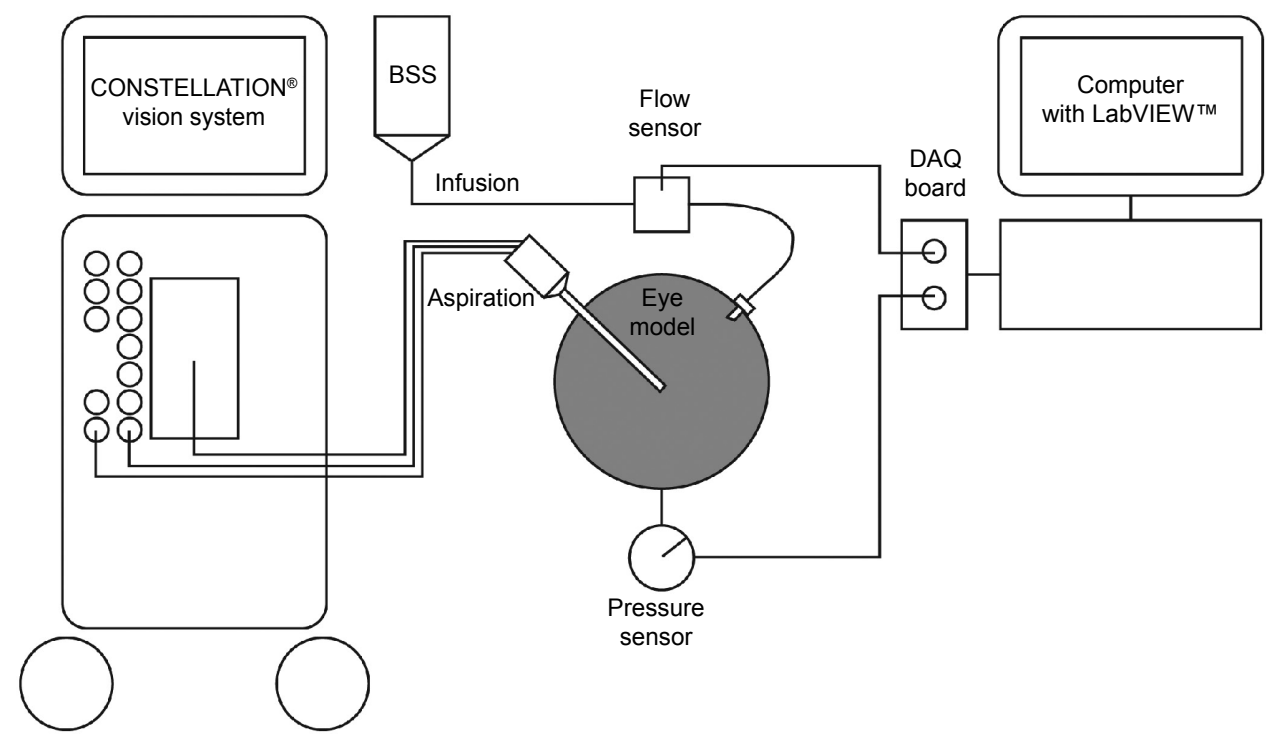

Figure 2 Experimental setup of the fluid-filled plastic eye model. Abbreviations: BSS, buffered saline solution; DAQ, data acquisition.

drop of triamcinolone was applied to the orange trocar hub, followed by rinsing with BSS. The external hub was checked for visible triamcinolone-stained vitreous protruding from the interior of the trocar cannula (Figure 3).

Figure 4 shows the setup for evaluating vitreous incarceration in animal cadaver eyes.

\section{Vitreous prolapse in rabbit cadaver eyes}

Two 23-gauge cannulas, one valved and one non-valved, were inserted into each of ten rabbit cadaver eyes. The cannula hubs were visually inspected to determine whether vitreous was present.

\section{Endoscopic visualization of vitreous incarceration in porcine cadaver eyes}

Twelve porcine cadaver eyes were prepared in the same way as the rabbit eyes. For each test in each eye, the same

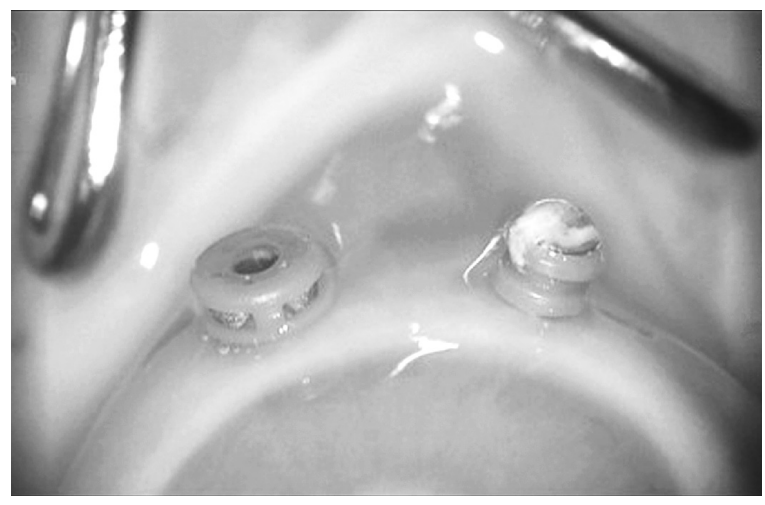

Figure 3 Intraoperative view of a valved (left) and a non-valved (right) cannula in a rabbit cadaver eye. size cannulas were used. Two valved trocar cannulas were inserted at the 4 and 6 o'clock positions for the endoilluminator and infusion cannula, respectively. For side-by-side comparisons of vitreous incarceration, one valved cannula was inserted at the 8 o'clock position and one non-valved cannula at the $10 \mathrm{o}$ 'clock position. The infusion pressure was set to $30 \mathrm{mmHg}$, and $0.04 \mathrm{~cm}^{3}$ of pure triamcinolone was injected through the sclera between the 8 o'clock valved cannula and 10 o'clock non-valved cannula (Figure 5), using a 30-gauge marked needle to yield the same depth in each test.

\section{Image analysis and statistical analyses}

Images of the rabbit and cadaver eyes were analyzed using Fiji (National Institutes of Health, Bethesda, MD, USA), an open-source platform for biomedical image analysis. ${ }^{14}$ A region of interest (ROI) $2 \mathrm{~mm}$ in diameter was centered around each cannula, and the region of incarcerated vitreous

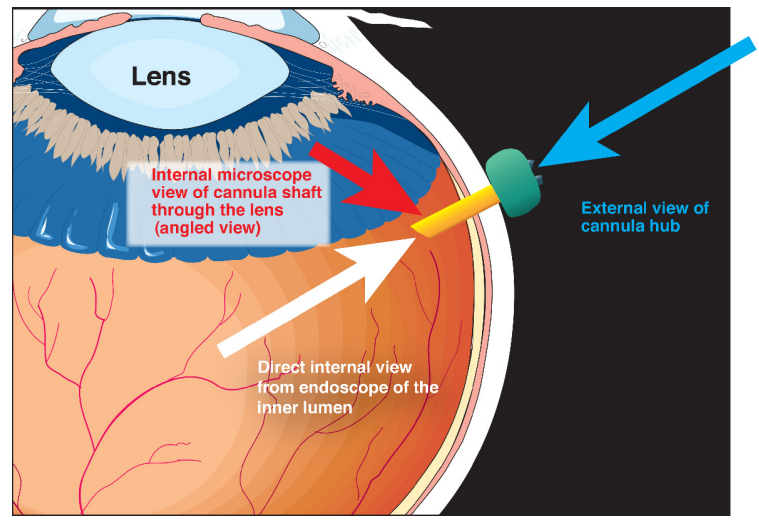

Figure 4 Experimental setup for evaluating vitreous incarceration in rabbit and porcine cadaver eyes. 


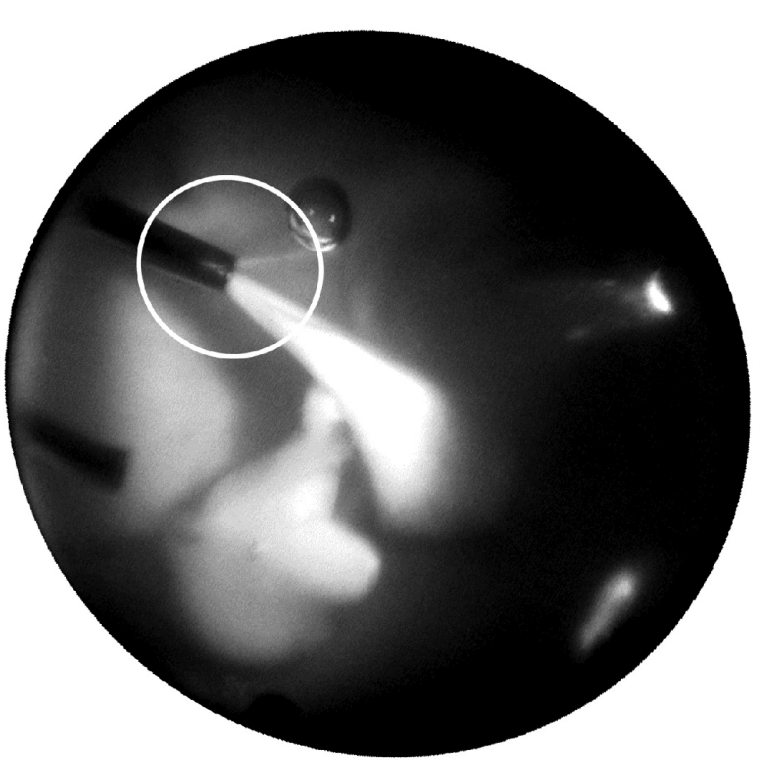

Figure 5 Intraoperative image of a rabbit cadaver eye.

Note: The encircled area indicates the region of interest (ROI) $2 \mathrm{~mm}$ in diameter centered around each cannula. The percent vitreous incarceration was calculated for the area within the circle.

within the ROI was outlined manually and its area calculated by the software. The ratio of this area to that of the ROI was defined as the percent incarcerated vitreous. Values for non-valved and valved cannulas were compared using Student's $t$-tests.

\section{Results}

\section{Air-filled model}

The largest drop in IOP was observed when both nonvalved cannulas were unoccupied (Table 1). When the air infusion was set to $30 \mathrm{mmHg}$ and both surgical instruments were removed from the non-valved cannula, the associated percent pressure drops below the IOP setting were $94 \%$, $92 \%$, and $89 \%$ for the 23-, 25-, and 27-gauge instruments, respectively. When one non-valved cannula was occupied with one instrument, the associated pressure losses were $83 \%, 77 \%$, and $76 \%$ for the $23-, 25$-, and 27 -gauge instruments, respectively. When both non-valved cannulas were

Table I Intraocular pressure $(\mathrm{mmHg})$ in the air-filled model

\begin{tabular}{|c|c|c|c|}
\hline & $\begin{array}{l}\text { Two cannulas } \\
\text { occupied }\end{array}$ & $\begin{array}{l}\text { One cannula } \\
\text { occupied }\end{array}$ & $\begin{array}{l}\text { Unoccupied } \\
\text { conditions }\end{array}$ \\
\hline \multicolumn{4}{|c|}{ Non-valved cannula } \\
\hline 23-gauge & 29.4 & 5.2 & 1.8 \\
\hline 25 -gauge & 29.8 & 6.8 & 2.6 \\
\hline 27 -gauge & 29.5 & 7.3 & 3.0 \\
\hline \multicolumn{4}{|c|}{ Valved cannula } \\
\hline 23-gauge & 28.4 & 28.4 & 28.6 \\
\hline 25 -gauge & 29.4 & 29.4 & 28.9 \\
\hline 27-gauge & 29.3 & 29.6 & 29.9 \\
\hline
\end{tabular}

Note: The intraocular pressure setting was $30 \mathrm{mmHg}$. occupied, pressure was closely maintained near the IOP setting for all instruments.

With valved cannulas, IOP ranged from 28.4 to $29.9 \mathrm{mmHg}$ for all test conditions (Table 1). Pressure loss with valved cannulas was $5 \%, 4 \%$, and $1 \%$ for the 23 -, 25 -, and 27 -gauge instruments, respectively.

\section{Fluid-filled model} Flow rate and IOP

With non-valved cannulas, IOP dropped while fluid leaked from the open ports. When one port was open and IOP compensation was off, the IOP dropped to approximately $40 \%$ of the set infusion pressure (Figure 6A). When IOP compensation was on, the drop was less at lower infusion pressures but the same at higher infusion pressures. When two ports were open, the IOP dropped to approximately $20 \%$ to $30 \%$ of the set infusion pressure, remaining unaffected by infusion pressure and IOP compensation settings (Figure 6B).

Valved cannulas maintained IOP at the set infusion pressure when one (Figure 6C) or two (Figure 6D) ports were left open. There was minimal to no leakage of fluid through the open ports at any infusion pressure level tested. IOP was maintained regardless of IOP compensation settings.

\section{Fluid dynamics}

At the trocar exits, the mean particle velocities of beads for the 23-, 25-, and 27-gauge non-valved cannulas were $1,636.70 \pm 147.76,1,443.65 \pm 136.67$, and $1,105.81 \pm 86.11 \mathrm{~mm} / \mathrm{s}$, respectively, and the jet diameters were $0.43,0.38$, and 0.30 $\mathrm{mm}$, respectively. At $5 \mathrm{~mm}$ from the trocar exits, the mean particle velocities of beads for the 23-, 25-, and 27-gauge non-valved cannulas were $602.21 \pm 304.31,186.20 \pm 122.78$, and $274.36 \pm 69.94 \mathrm{~mm} / \mathrm{s}$, respectively, and the jet diameters were $0.97,0.84$, and $0.46 \mathrm{~mm}$, respectively. In contrast, valved cannulas did not generate an infusion jet; therefore, jet geometry and particle velocity could not be measured.

\section{Vitreous-filled models}

\section{Vitreous incarceration in rabbit cadaver eyes}

Analysis of direct microscopic images of rabbit eyes showed that vitreous incarceration was significantly greater with 23 -gauge non-valved than with 23-gauge valved cannulas (24\% $\pm 6 \%$ versus $2 \% \pm 1 \%, P<0.005$ ) (Figure 7 ).

\section{Vitreous prolapse in rabbit cadaver eyes}

Direct observation of the external cannula hub showed that vitreous prolapsed through the non-valved cannula in all ten rabbit eyes, whereas there was no prolapse through valved cannulas. 


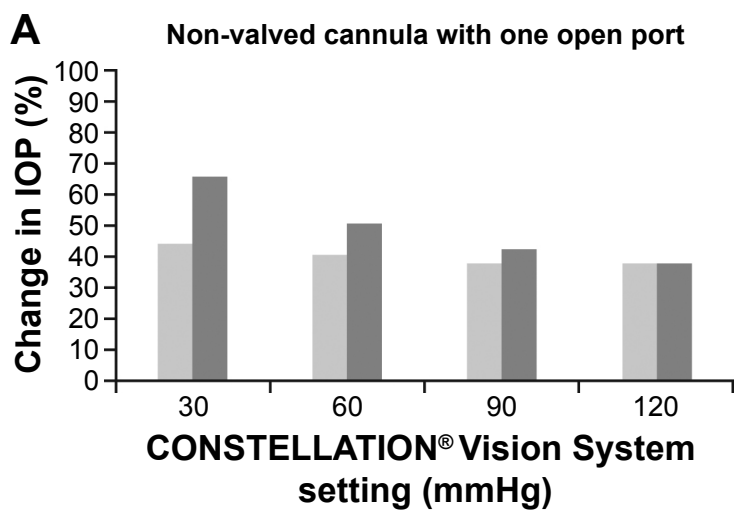

C Valved cannula with one open port

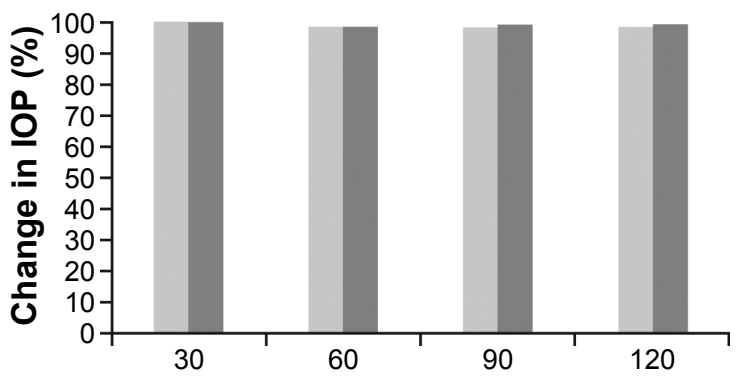

CONSTELLATION ${ }^{\circledR}$ Vision System setting $(\mathrm{mmHg})$

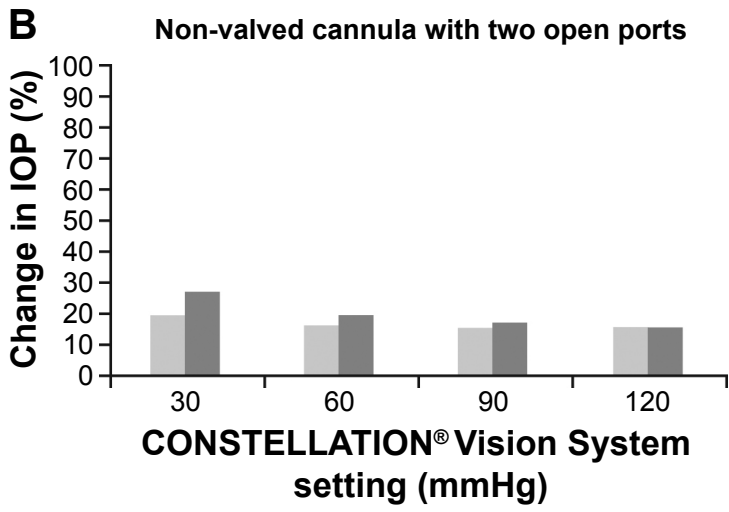

D Valved cannula with two open ports

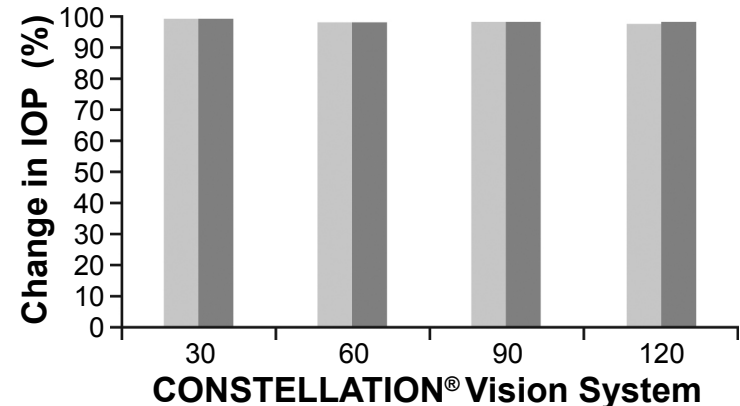

setting $(\mathrm{mmHg})$

Figure 6 Fluid-filled plastic eye model: change in IOP, taking the 25-gauge cannula as an example.

Notes: (A) Non-valved trocar cannula, one port open. (B) Non-valved trocar cannula, two ports open. (C) Valved trocar cannula, one port open. (D) Valved trocar cannula, two ports open.

Abbreviation: IOP, intraocular pressure.

\section{Vitreous incarceration in porcine cadaver eyes}

Internal endoscopic analysis of porcine eyes showed that vitreous incarceration was significantly greater with 23 -gauge $(27 \% \pm 16 \%$ versus $0 \% \pm 0 \%, P<0.05)$ and 27 -gauge $(30 \% \pm 16 \%$ versus $0 \% \pm 0 \%, P<0.05)$ non-valved than valved cannulas (Figure 8). Vitreous incarceration was also greater for 25-gauge non-valved than 25-gauge valved cannulas, but the difference was not statistically significant $(46 \% \pm 46 \%$ versus $1 \% \pm 3 \%, P=0.10$ ).

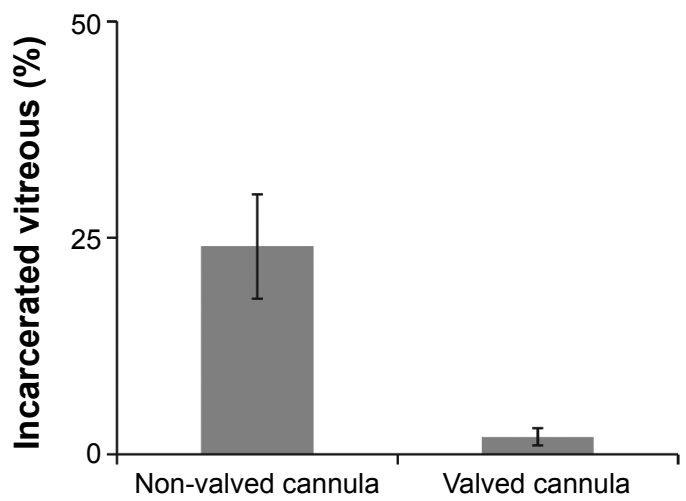

Figure 7 Vitreous incarceration in rabbit cadaver eyes.

\section{Discussion}

In the air-filled rubber eye model, occupation of zero or one non-valved cannula resulted in drastic pressure loss. In a clinical setting, these drastic pressure drops can be associated with temporary globe collapse or severe complications, such as suprachoroidal hemorrhage or intraoperative hemorrhage in a patient with diabetic retinopathy. Occupation of both non-valved cannulas created a closed system within the eye,

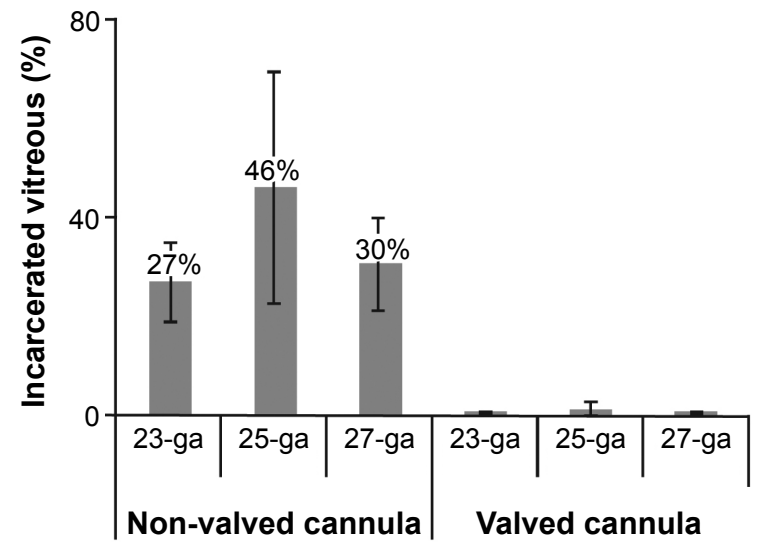

Figure 8 Vitreous incarceration in porcine cadaver eyes. Abbreviation: ga, gauge. 
with IOP maintained near its $30 \mathrm{mmHg}$ setting. However, surgery involves instrument exchange, which will result in large pressure fluctuations when non-valved cannulas are used.

Valved cannulas in the air-filled eye model maintained IOP close to the set value of $30 \mathrm{mmHg}$ during both occupied and unoccupied test conditions. Overall, there was minimal pressure loss with valved $(1 \%-5 \%)$ compared with non-valved $(76 \%-94 \%)$ cannulas. The ability of valved cannulas to maintain IOP close to the desired setting suggests that their use can result in reduced IOP fluctuations and improved globe stability throughout vitrectomy.

The results in the fluid-filled acrylic eye model were similar to those in air-filled eyes. Valved trocar cannulas maintained IOP at the set infusion pressure when one or two ports were left open, as occurs during instrument exchange. There was minimal to no leakage of fluid through the open ports at any infusion pressure tested. In contrast, when nonvalved trocar cannulas were used, IOP dropped while fluid leaked from open ports.

We found that, for all three gauges of non-valved cannulas, particle velocities were lower $5 \mathrm{~mm}$ from the trocar exit than at the trocar exit, while the diameter of the particle stream was greater $5 \mathrm{~mm}$ from the trocar exit than at the trocar exit. In contrast, valved cannulas have no fluid motion and no infusion jet. Thus, valved cannulas demonstrate better globe stability than non-valved cannulas.

Vitreous incarceration was significantly lower using valved than non-valved cannulas, as determined by direct microscopic visualization in rabbit cadaver eyes and endoscopic visualization in porcine cadaver eyes. Moreover, vitreous prolapse occurred through non-valved cannulas but was not observed through valved cannulas.

Experimental testing in a laboratory setting allowed standardization of the tests but had inherent limitations. These included reliance on model systems and cadaveric eyes as well as high variability of vitreous. Small sample sizes were another limitation of this study. It would be beneficial to compare the impact of valved and non-valved cannulas in live animals and in clinical settings.

In summary, valved cannulas surpassed non-valved cannulas in maintaining IOP in air-filled and fluid-filled model eyes, reducing fluid leak in fluid-filled model eyes, and reducing vitreous incarceration in vitreous-filled animal cadaver eyes. Valved cannulas may be the optimal choice of trocar cannulas for vitrectomy.

\section{Acknowledgments}

The authors wish to thank Ramon Dimalanta, Tingting Wang, and David Loke for their support with data collection and analysis.

\section{Disclosure}

Dina Joy Abulon is an employee of Alcon Laboratories, Inc. Dr Martin Charles is a consultant to Alcon Laboratories, Inc. BelMed Professional Resources, Inc. and Faith Reidenbach provided editorial support which was contracted and funded by Alcon. Daniel E Charles reports no conflict of interest in this work.

\section{References}

1. Ohm J. Über die Behandlung der Netzhautablösung durch operative Entleerung der subretinalen Flussigkeit und Einspritzung von Luft in den Glaskorper. [On the treatment of retinal detachment by surgical removal of the subretinal liquid and injection of air into the vitreous]. Graefes Arch Klin Ophthalmol. 1911;79:442-450. German

2. Rosengren B. Results of treatment of detachment of the retina with diathermy and injection of air into the vitreous. Acta Ophthalmol. 1938;16:573-579.

3. Machemer R, Buettner H, Norton EW, Parel JM. Vitrectomy: apars plana approach. Trans Am Acad Ophthalmol Otolaryngol. 1971;75(4): 813-820.

4. Tardif YM, Schepens CL, Tolentino FI. Vitreous surgery. XIV. Complications from sclerotomy in 89 consecutive cases. Arch Ophthalmol. 1977;95(2):229-234.

5. Shimada H, Nakashizuka H, Hattori T, Mori R, Mizutani Y, Yuzawa M. Clear visualization of anterior vitreous incarceration into cannulae during 25-gauge vitrectomy in eyes with asteroid hyalosis. Eur J Ophthalmol. 2012;22(2):293-295.

6. Koch FH, Luloh KP, Singh P, Scholtz S, Koss M. 'Mini-gauge' pars plana vitrectomy: 'inside-out view' with the GRIN solid rod endoscope. Ophthalmologica. 2007;221(5):356-362.

7. Buettner H, Machemer R. Histopathologic findings in human eyes after pars plana vitrectomy and lensectomy. Arch Ophthalmol. 1977; 95(11):2029-2033.

8. Tan HS, Mura M, de Smet MD. Iatrogenic retinal breaks in 25-gauge macular surgery. Am J Ophthalmol. 2009;148(3):427-430.

9. Gosse E, Newsom R, Lochhead J. The incidence and distribution of iatrogenic retinal tears in 20-gauge and 23-gauge vitrectomy. Eye (Lond). 2012;26(1):140-143.

10. Sabti K, Kapusta M, Mansour M, Overbury O, Chow D. Ultrasound biomicroscopy of sclerotomy sites: the effect of vitreous shaving around sclerotomy sites during pars plana vitrectomy. Retina. 2001;21(5):464-468.

11. Hikichi T, Kitamei H, Kosaka S, Shioya S, Takami K. Intraoperative endoscopic observation of sclerotomy site after cannula removal for 23-gauge vitrectomy. Clin Ophthalmol. 2014;8:477-481.

12. Benitez-Herreros J, Lopez-Guajardo L, Camara-Gonzalez C, Silva-Mato A. Effect of interposition maneuver during cannula removal on vitreous incarceration rate in vitrectomized eyes measured by ultrasound biomicroscopy. Curr Eye Res. 2012;37(9):809-812.

13. Benitez-Herreros J, Lopez-Guajardo L, Camara-Gonzalez C, Silva-Mato A. Influence of the interposition of a nonhollow probe during cannula extraction on sclerotomy vitreous incarceration in sutureless vitrectomy. Invest Ophthalmol Vis Sci. 2012;53(11):7322-7326.

14. Schindelin J, Arganda-Carreras I, Frise E, et al. Fiji: an open-source platform for biological-image analysis. Nat Methods. 2012;9(7): 676-682. 


\section{Publish your work in this journal}

Clinical Ophthalmology is an international, peer-reviewed journal covering all subspecialties within ophthalmology. Key topics include: Optometry; Visual science; Pharmacology and drug therapy in eye diseases; Basic Sciences; Primary and Secondary eye care; Patient Safety and Quality of Care Improvements. This journal is indexed on

PubMed Central and CAS, and is the official journal of The Society of Clinical Ophthalmology (SCO). The manuscript management system is completely online and includes a very quick and fair peer-review system, which is all easy to use. Visit http://www.dovepress.com/ testimonials.php to read real quotes from published authors. 